\title{
Lipossarcoma Gigante da Vulva: relato de caso
}

\author{
Vulval Giant Liposarcoma: a case report \\ Denise Gonçalves Priolli, Carlos Augusto Real Martinez \\ Fillipo Campione, José Geraldo Leme de Araújo \\ Jaques Waisberg, Enzo Magrini
}

\begin{abstract}
RESUM0
O lipossarcoma é neoplasia rara, originária das células mesenquimais primitivas e, entre os sarcomas, é o tipo histológico mais freqüente. Acomete principalmente os membros, podendo atingir outras regiões, sendo rara a localização genital. Os autores relatam caso de lipossarcoma vulvar em paciente de 27 anos, que apresentava massa de crescimento progressivo que limitava a deambulação. O exame fisico mostrava tumor vulvar volumoso $e$ ulcerado. A doente foi submetida à ressecção local, tendo o exame histopatológico diagnosticado lipossarcoma bem diferenciado com margens livres de comprometimento. Atualmente a enferma encontra-se bem, sem recidiva da doença, 24 meses após a cirurgia.
\end{abstract}

PALAVRAS-CHAVE: Vulva: câncer. Sarcomas.

\section{Introdução}

Os lipossarcomas, tumores originários da célula mesenquimal primitiva, representam $15 \%$ de todos os sarcomas de partes moles ${ }^{1}$. São tumores raros que ocorrem, geralmente, em pessoas idosas e que aparecem, quase sempre, em locais onde existe acúmulo de tecido adiposo ${ }^{2,3}$. Esses tumores atingem com maior freqüencia os membros inferiores e superiores, o tronco e o abdômen, sendo excepcional sua localização na região vulvar, onde representam apenas 1 a $2 \%$ das neoplasias malignas ${ }^{4}$. A revisão da literatura confirma a raridade deste tipo de localização quando se verifica o pequeno número de casos publicados ${ }^{5}$.

Na maioria das vezes o lipossarcoma da região vulvar apresenta-se como lesão única, de pequeno ou médio porte, e sua aparência macroscópica circunscrita leva, freqüentemente, ao diagnóstico errôneo de doença benigna ${ }^{3,5}$. Este retardo no diagnóstico faz com que um número não desprezivel de doentes procure atendimento

Disciplinas de Cirurgia Geral e Anatomia Patológica da Faculdade de Medicina da Universidade São Francisco, Bragança Paulista (SP)

Correspondência:

Denise Gonçalves Priolli

Rua São Vicente, 614 - Jardim Paulista

12941-000 - Atibaia - SP

e-mail: depriolli@uol.com.br médico com lesões avançadas, diminuindo com isso a possibilidade de cura.

O interesse na publicação deste relato é demonstrar a presença de neoplasia raramente observada, de localização e dimensões pouco freqüentes, numa faixa etária excepcionalmente atingida e que após tratamento cirúrgico apresentou evolução favorável.

\section{Relato do Caso}

Paciente do sexo feminino, 27 anos, branca, referia há um ano o aparecimento de massa na região vulvar direita, indolor, de crescimento progressivo, que passou a dificultar a deambulação. Negava perda ponderal significativa no período e relatava ainda a presença ocasional de secreção sanguinolenta que sujava as vestes.

O exame físico geral era normal. O exame da região perineal mostrava a presença de massa de aproximadamente $30 \mathrm{~cm}$ em seu maior diâmetro, móvel, indolor, pediculada, de consistência fibroelástica, que se iniciava no terço inferior do grande lábio vulvar direito atingindo a região perianal. A lesão apresentava ulceração central superficial, na extremidade caudal, recoberta parcialmente por uma crosta de fibrina (Figura 1). 


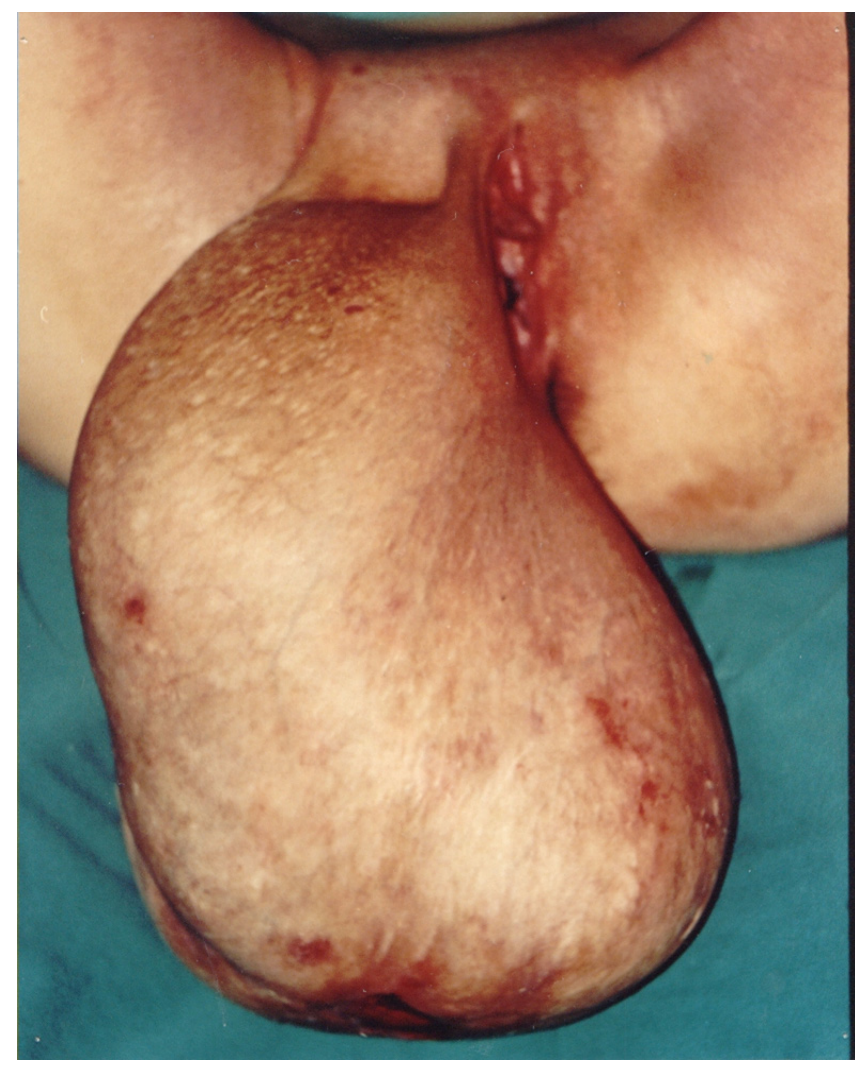

Figura 1 - Tumor no grande lábio vulvar direito e região perianal.

O toque vaginal demonstrava que a lesão não infiltrava a parede vaginal e no toque o reto encontrava-se preservado. Não havia linfoadenomegalia na região inguinal.

O exame hematológico completo não apresentava alterações (Hb: 14,4 g/dL, Ht: 38\%, leucócitos 9.380 e plaquetas $282.000 / \mathrm{mm}^{3}$ ) e os exames bioquimicos revelavam glicemia de $92 \mathrm{mg} / \mathrm{dL}$, uréia $24 \mathrm{mg} / \mathrm{dL}$, creatinina $0,3 \mathrm{mg} / \mathrm{dL}$, TC $4 \mathrm{mi}-$ nutos e anti-HIV negativo. A radiografia de tórax, a ultra-sonografia abdominal e a tomografia computadorizada do abdômen não mostravam a presença de metástases.

Após bloqueio anestésico peridural, a doente foi submetida a ressecção local, respeitando-se margem de três centímetros, realizada com facilidade em virtude de a lesão apresentar-se pediculada em sua base. A ferida cirúrgica foi tratada por meio de sutura primária sem necessidade de rotação de retalho cutâneo. A excisão cirúrgica realizada permitiu a preservação da anatomia local, não havendo necessidade de remoção do grande lábio vulvar direito.

O tumor, com dimensões de 33 por 24,5 por $10 \mathrm{~cm}$, pesando $4.400 \mathrm{~g}$, era recoberto por retalho de pele em quase toda extensão, com lesão escarificada de $4,5 \times 2,0 \mathrm{~cm}$ em sua extremidade caudal. O exame microscópico demonstrou neoplasia mesenquimal constituída por células adiposas predominantemente maduras, septadas por faixas de tecido fibroso que delimitavam lóbulos irregulares. Nesses septos estavam presentes lipoblastos com núcleos irregulares, hipercromáticos e atípicos, permeados por células fusiformes (Figura 2). As margens cirúrgicas se mostraram livres de comprometimento neoplásico. Os achados do exame histopatológico firmaram o diagnóstico de lipossarcoma bem diferenciado, com baixo potencial de malignidade. Segundo o Sistema TNM a doença foi classificada como estádio IB. No momento a paciente encontra-se bem, sem sinais de recidiva da doença 24 meses após a ressecção cirúrgica.

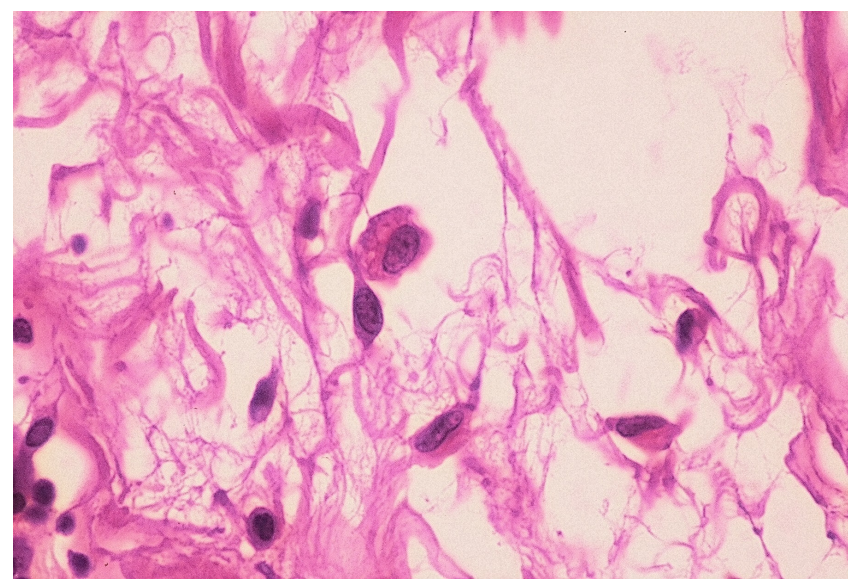

Figura 2 - Fotomicrografia mostrando lipoblastos com núcleos irregulares, hipercromáticos e atípicos, com vacúolos de lípide no citoplasma, permeados por células fusiformes (HE 400X).

\section{Discussão}

Os sarcomas de partes moles são tumores raros. Tal constatação fica mais evidente ao verificarmos estatísticas mostrando que nos Estados Unidos surgem aproximadamente 6.000 casos novos por ano ${ }^{6}$. Considerando-se que os fatores geográficos e raciais parecem não ter importância na etiologia dessa neoplasia e respeitando-se ainda os índices demográficos específicos de cada país, estima-se que no Brasil devam existir cerca de 3.500 casos novos por ano ${ }^{6}$.

Dos sarcomas de partes moles o lipossarcoma é o tipo histológico maligno mais freqüente, geralmente surgindo em áreas onde existe acúmulo de tecido adiposo ${ }^{1-3,7}$. Na maioria das vezes são encontrados, em ordem decrescente, nos membros inferiores, membros superiores, tronco, cabeça e pescoço, retroperitônio e mediastino ${ }^{1,2,6}$. A localização vulvar é rara e este fato pode ser con- 
firmado ao verificarmos que de 1966 até o presente só pudemos encontrar 16 casos publicados ${ }^{4,5,8-}$ ${ }^{14}$. Talvez esse número possa até ser maior pelo fato de não existir uniformidade na denominação de todas as variantes histopatológicas da neoplasia.

As lesões geralmente são únicas e raramente atingem grandes proporções. Em virtude de a localização do tumor permitir o auto-exame e conseqüentemente o diagnóstico precoce, a enferma quando procura auxílio médico possui, na maioria das vezes, tumores de pequeno ou médio porte. Os tumores de maiores dimensões são encontrados em locais de acesso difícil, tais como o retroperitônio e o mediastino ${ }^{2,6,7}$. Tumores de grandes proporções são vistos em regiões superficiais do corpo com menor freqüência ${ }^{8}$. Cabe destacar que no caso que acompanhamos, não obstante o local permitir o auto-exame, a neoplasia apresentava dimensões consideráveis, chegando a impedir a deambulação normal.

A velocidade de crescimento deste tipo de neoplasia está diretamente relacionada ao seu grau de diferenciação celular. Tumores de baixo grau apresentam crescimento lento, infiltrando os tecidos e órgãos vizinhos ${ }^{1}$. Recentemente descreveu-se variedade bem circunscrita da neoplasia, que ocorre principalmente em doentes jovens, de crescimento lento, pouca agressividade e que possui bom prognóstico após a simples excisão local ${ }^{13}$. Tal variedade clínica, semelhante à da enferma que acompanhamos, é conhecida por várias denominações, sendo lipossarcoma bem diferenciado, lipoma atípico, lipoblastoma-símile e lipossarcoma mixóide as mais empregadas ${ }^{13-16}$. A expressão imuno-histoquímica da vimetina e da proteína S100 sugerem o caráter maligno dessa variante, não obstante possuírem uma evolução clínica lenta e gradual ${ }^{13,16}$.

Nos tumores indiferenciados esse crescimento é mais rápido, acompanhado de invasão loco-regional e disseminação metastática por via hematogênica. Essa forma de disseminação parece estar relacionada com a graduação histológica ao constatar-se que as metástases pulmonares acontecem em $14 \%$ dos tumores de baixo grau, e em mais de $50 \%$ nos tumores de alto grau ${ }^{1}$. Com freqüência menor as metástases se disseminam por via linfática ${ }^{3,7}$.

O lipossarcoma pode acometer todas as faixas etárias, sendo mais freqüente, porém, a partir da sexta década ${ }^{4}$. Essa mesma característica já não é tão evidente quando o tumor localiza-se na vulva. Dos 16 casos publicados, verifica-se em cinco deles que a neoplasia ocorreu em faixa etária mais precoce ${ }^{5,12-14}$, assim como no caso que pudemos acompanhar. A doença não tem, aparentemente, predisposição racial ${ }^{2,7}$.
A principal manifestação clínica, na maior parte dos casos, é a presença de massa indolor que progressivamente aumenta de tamanho abaulando a pele subjacente e tornando-a lisa e brilhante. À medida que o tumor progride, em virtude de fenômenos isquêmicos ou pela infiltração neoplásica, a pele adquire tonalidade escurecida, evoluindo com freqüência para necrose e ulceração ${ }^{7,9}$. Tal aspecto também foi por nós verificado.

O diagnóstico clínico geralmente é dificil e na maioria das vezes a doença é diagnosticada como lipoma ${ }^{3-5,10}$. Entretanto, algumas características podem auxiliar no diagnóstico diferencial. O lipossarcoma apresenta crescimento mais rápido, tem caráter infiltrativo loco-regional mais nítido, possui uma consistência maior devido à proliferação celular mais intensa ${ }^{1,3}$. No caso que acompanhamos embora essas características estivessem presentes, não permitiam diagnóstico pré-operatório de certeza.

Os exames de imagem no lipossarcoma da região vulvar são úteis para o estadiamento da doença. Assim, a radiografia e a tomografia computadorizada do tórax e a tomografia do abdômen são de grande valia na pesquisa de metástases pulmonares ou hepáticas, respectivamente $^{16}$. A radiografia simples, a tomografia e a ressonância magnética da região pélvica podem contribuir para a avaliação da infiltração do reto, vagina, útero, ossos e grandes vasos inguinais ${ }^{15,17}$. Acreditamos que as ultra-sonografias endovaginal e endorretal possam ser úteis na avaliação locoregional, ao verificar-se o importante papel que possuem no estadiamento de outros tumores da região pélvica. Na doente que acompanhamos a radiografia de tórax revelou-se normal para pesquisa de metástases pulmonares. Da mesma forma, a tomografia computadorizada de abdômen total não demonstrou presença de metástases hepáticas ou linfonodais, bem como não evidenciou comprometimento dos órgãos da região pélvica.

A punção-biópsia com agulha fina guiada pela tomografia ou ultra-sonografia pode ser empregada no diagnóstico histopatológico. Contudo, cabe destacar que em virtude de a neoplasia apresentar áreas de aspecto histológico variável e de difícil interpretação, a quantidade de material a ser examinado deverá ser substancial, preconizando-se então a utilização de agulhas de grosso calibre $^{1,8}$. A biópsia excisional é reservada exclusivamente para os casos de tumores pequenos e superficiais. Tal procedimento não deve ser realizado em tumores maiores, mesmo quando pareçam completamente ressecáveis, pois a ressecção curativa depende da remoção completa do tumor em monobloco com as estruturas que o envol$v^{\text {vem }}{ }^{17}$. O exame histopatológico do lipossarcoma 
revela que a neoplasia possui falsa cápsula que nada mais é do que reação inflamatória na periferia do tumor ${ }^{3,8,9}$. Quando existe a progressão através dessa pseudocápsula, as células neoplásicas infiltram estruturas adjacentes. O conhecimento desse fato é importante no tratamento cirúrgico, fazendo com que a ressecção deva ser realizada respeitando uma margem ampla e distante o suficiente dos limites macroscópicos do tumor. Na enferma que acompanhamos ressecou-se a lesão respeitando margem de três centímetros, tendo o exame microscópico mostrado que se encontravam livres de comprometimento neoplásico. A recidiva parece estar diretamente relacionada com ressecção incompleta ${ }^{7,16}$.

A determinação do grau de malignidade também é importante na programação terapêutica. Em geral, estes tumores são classificados de I a IV segundo o grau de diferenciação celular ${ }^{8}$. Tumores com alto grau histológico de malignidade podem apresentar diagnóstico histopatológico dificil, sendo freqüentemente confundidos com os fibrossarcomas e histiocitomas ${ }^{16,18}$. Atualmente os parâmetros mais utilizados para a graduação dos sarcomas são: diferenciação e proliferação celular, vascularização, quantidade de necrose e número de mitoses ${ }^{3,6,8}$.

Estudos recentes têm procurado correlacionar a expressão imuno-histoquímica da proteína S-100, da vimetina, dos genes P-53, Ki-67, h-mdm2 e da ploidia com o prognóstico dos sarcomas de partes moles ${ }^{7,13,16}$. Os resultados ainda são controversos na maioria das vezes, todavia, tem-se demonstrado que tumores classificados dentro de subgrupos semelhantes apresentam características biológicas e moleculares diferentes, o que pode justificar comportamento clínico e resposta terapêutica diferentes ${ }^{1,6}$.

Tumores com baixo grau de malignidade são tratados, à semelhança do que realizamos, com ressecção local que respeite margens cirúrgicas adequadas ${ }^{17,18}$. O conceito de ressecção tridimensional, na qual a neoplasia deverá estar envolvida, em todos os sentidos, por um a dois centímetros de tecido normal é fundamental para reduzir a chance de recidivas ${ }^{7}$. Na doente do presente relato a lesão encontrava-se em íntimo contato com a pele, o que nos obrigou a realizar a ressecção respeitando margem mínima de três centímetros.

Nos tumores volumosos ou de localização profunda o emprego da radioterapia prévia seguida da extirpação cirúrgica vem sendo preconizado, com o intuito de diminuir o tamanho da lesão, permitindo operações menos mutiladoras ${ }^{19,20}$. Nos tumores não passiveis de ressecção cirúrgica radical na avaliação inicial, a quimioterapia e a ra- dioterapia neoadjuvantes, seguidas de ressecção marginal e complementação com radioterapia externa ou braquiterapia, são alternativas também utilizadas ${ }^{17,19}$.

Nas enfermas portadoras de lesões com alto grau de malignidade, submetidas à cirurgia prévia não adequada ou que apresentaram recidiva local, a ressecção cirúrgica com ampliação das margens seguida de radioterapia tem sido conduta recentemente proposta ${ }^{17}$.

O esvaziamento linfático concomitante com a excisão local deve ser reservado para casos em que existe disseminação para linfonodos inguinais. Linfadenectomia inguinal profilática não é indicada, em virtude de estes tumores apresentarem disseminação linfática rara, assim como pelas seqüelas que esse tipo de procedimento acarreta ${ }^{14}$.

Na doente que acompanhamos, não obstante o tamanho, a lesão apresentava baixo grau de malignidade, além de permitir a ressecção cirúrgica adequada. Dessa forma, optou-se pela excisão local isolada, sem radioterapia adjuvante. Tal proposta terapêutica vem sendo preconizada por centros de grande experiência no tratamento dos sarcomas de partes moles ${ }^{7,8,17}$. A evolução pós-operatória, sem evidências de recidiva neoplásica até a presente data, respalda a conduta realizada.

\section{ABSTRACT}

Liposarcoma is a rare neoplasia that originates from primitive mesenchymal cells and is the most common histological type of sarcoma. It mainly affects the limbs but can reach other regions. Genital localization is, however, rare. The authors report a case of vulvar liposarcoma in a 27-year-old patient, who presented a progressively growing mass that limited her movements. Physical examination showed a large ulcerated vulvar tumor. The patient underwent local resection and histopathological examination diagnosed a well-differentiated liposarcoma with uncompromised margins. At the present time, 24 months after surgery, the patient is well and without recurrence of the disease.

KEYWORDS: Vulvar: cancer. Sarcoma.

\section{Referências}

1. Gill PG. Sarcoma de partes moles. In: Hossfeld DK, Sherman CD, Love RD, Bosch FX, editores. Manual de Oncologia Clínica. $6^{\mathrm{a}}$ ed. São Paulo: Fundação Oncocentro de São Paulo; 1999. p.469-76. 
2. Abeloff MD, Armitage JO, Lichter AS, Niederhuber JE. Clinical oncology. $2^{\text {nd }}$ ed. New York: Churchill Livingstone; 2000. p. 1963.

3. Rosenberg A. Ossos, articulações e tumores de partes moles. In: Cotran RS, Kumar V, Collins T. Robbins Patologia Estrutural e Funcional. $6^{\mathrm{a}}$ ed. Rio de Janeiro: Guanabara Koogan; 2000. p.1087-134.

4. Rogers RG, Thorp JM Jr. Liposarcoma of the vulva: a case report. J Reprod Med 1995; 40:863-4.

5. Yokouchi J, Negishi Y, Abe K, Shirasawa K, Mernyei M. Radiotherapy for liposarcoma of the vulva. Gynecol Oncol 2000; 79:315-7.

6. Nascimento A, Oliveira AM. Sarcoma de partes moles. In: Lopes A, editor. Patologia Geral. $1^{\text {a }}$ ed. Rio de Janeiro: Medsi; 1999. p.41-68.

7. Lopes A, Rossi BM, Nakagawa WT. Sarcoma de partes moles no adulto. In: Kowalski LP, Sabbaga J, Fogaroli RC, editores. Manual de Condutas Diagnósticas e Terapêticas em Oncologia. $1^{\text {a }}$ ed. São Paulo: Âmbitos; 1996. p. 489-500.

8. Nucci MR, Fletcher CD. Liposarcoma (atypical lipomatous tumors) of the vulva: a clinicopathologic study of six cases. Int J Gynecol Pathol 1998; 17:17-23.

9. Vecchione A, Palazzetti P. Anatomoclinical considerations on a case of liposarcoma with vulvar localization. Riv Anat Patol Oncol 1967; 31:177-93.

10.Carlà TG, D'Ambrosio E, Vetrugno M, Filotico M. Atypical lipoma, floret-like pleomorphic variant. A lipomatous lesion simulating a liposarcoma. Pathologica 1989; 81:679-85.

11.Brooks JJ, LiVolsi VA. Liposarcoma presenting on the vulva. Am J Obstet Gynecol 1987; 156:73-5.
12.Genton CY, Maroni ES. Vulval liposarcoma. Arch Gynecol 1987; 240:63-6.

13.Lae ME, Pereira PF, Keeney GL, Nascimento AG. Lipoblastoma-like tumour of the vulva: report of three cases of a distinctive mesenchymal neoplasm of adipocytic differentiation. Histopathology 2002; 40:505-9.

14.Donnellan R, Moodley M. Vulval myxoid liposarcoma. Int J Gynecol Cancer 2001; 11:321-2.

15. Mentzel T, Fletcher CD. Lipomatous tumours of the soft tissues: an update. Virchows Arch 1995; 427:353-63.

16. Hashimoto H, Daimaru Y, Enjoji M. S-100 protein distribution in liposarcoma. An immunoperoxidase study with special reference to the distinction of liposarcoma from myxoid malignant fibrous histiocytoma. Virchows Arch A Pathol Anat Histopathol 1984; 405:1-10.

17.Ferreira FO, Lopes A. Qual a sua orientação em sarcoma de partes moles? Bol Inf Col Bras Cir 2001; 32:10-2.

18.Krause U, Richter HJ, Schulz U, Eigler FW. Surgical therapy of liposarcoma. Chirurg 1983; 54:664-8.

19.Sadoski C, Suit HD, Rosenberg A, Mankin H, Efird $\mathrm{J}$. Preoperative radiation, surgical margins, and local control of extremity sarcomas of soft tissues. J Surg Oncol 1993; 52:223-30.

20.Suit H, Spiro IJ. Soft tissue sarcomas: radiation as a therapeutic option. Ann Acad Med Singapore 1996; 25:855-61. 